\title{
A Survey on English Majors’ Dynamic Trends of Dictionaries Using
}

\author{
Xixiang Lou ${ }^{1,2}$, Liping $\mathrm{Li}^{1}$ \\ ${ }^{1}$ Faculty of Foreign Languages, Nanjing Normal University, Nanjing, China \\ ${ }^{2}$ Department of Foreign Languages and Literatures, Zhangzhou Normal University, Zhangzhou, China \\ Email: lou_xx@163.com,412183996@qq.com
}

Received April 22 ${ }^{\text {nd }}, 2012$; revised May 22 ${ }^{\text {nd }}, 2012$; accepted May $30^{\text {th }}, 2012$

\begin{abstract}
English dictionaries are the necessary tools for English learning, because a good dictionary is a stable resource of language knowledge. Proper dictionary using can stimulate students' interest, and cultivate their self-autonomy in language learning. With the development of dictionary compiling technology, a variety of dictionaries have come into existence. The most-often-used dictionaries are paper dictionaries and electronic ones. It is assumed by some that the habit of dictionary using can influence the efficiency of the students' language learning. This article reports on a survey of the diachronic trends of English major seniors (415) in their choice of dictionaries in the course of English learning from junior middle school to the college education. The investigation is to get some information about the subjects' habits in dictionary-using at different stage of schooling.
\end{abstract}

Keywords: EFL Learners; Dictionary Using; Survey

\section{Introduction}

In the process of English learning, a high-quality dictionary is a good friend and teacher for EFL learners. The study of dictionary use in EFL learning is one of the important areas of Applied Linguistics research. With the development of science technology, different kinds of dictionaries come into being. Students can choose whatever he or she likes. However, these dictionaries are quite different from each other in both the amount of information and the format of information presentation. In fact, these dictionaries are usually designed for different learners on different occasions. If the learners choose the proper ones for their study, they will benefit a lot. Otherwise, the "best teacher" will not benefit them much and sometimes may cause some problems for their learning. Paper dictionaries and electronic dictionaries are the most common in classroom EFL learning and they are quite different from each other in both the history of development and some other aspects. English-dictionary using is an important English learning strategy, which has attracted researchers' attention, and the choice of dictionaries is one focus under such a topic. Till now very few researches have been made on the EFL learners' choice between paper dictionaries and electronic ones. This paper will make a report on a survey of 415 EFL learners' diachronic change in their choice of English dictionaries between paper dictionaries and electronic dictionaries (pocket electronic dictionary).

\section{The History of English Dictionary}

The English dictionary compilation has a more-than-fourhundred-year-long history. Lin and Liu (2006) summarized the history of English dictionaries into five periods:

1) The first period: from the Middle Ages to the end of the 16th century. It is a period of glossary-making.

2) The second period: the beginning of the 17 th century. It is a period of glossary dealing with hard words.

3) The third period: from the middle 17th century to the end of the century. It is a period when etymology of words is added to the meaning.

4) The fourth period: the whole 18th century. It is a period of now called English dictionaries when dictionaries had established the standards of spelling, meaning and usage of English words.

5) The fifth period: from the 19th century to the 20th century. It is a period when English dictionaries saw much improvement and maturity.

\section{The Classification of English Dictionaries}

Li and Zhou (2001) classified dictionaries in 9 different ways:

1) Contents: philological dictionaries, encyclopedic dictionaries and special dictionaries.

2) Scope of words collected and the information of the vocabularies provided: general-purpose dictionaries and specialized dictionaries.

3) Languages involved: monolingual dictionaries, bilingual dictionaries and multi-lingual dictionaries.

4) History periods involved: diachronic dictionaries and synchronic dictionaries.

5) Size: unabridged dictionaries, desk dictionaries and pocket dictionaries.

6) Service objects: for foreigners and for natives.

7) Main functions: active dictionaries and passive dictionaries.

8) Arrangement of entries: systematic dictionaries and alphabetically dictionaries.

9) Medium: paper dictionaries and electronic dictionaries. Furthermore, the electronic dictionaries can be further divided into three kinds: pocket dictionaries, CD-ROM dictionaries and online dictionaries. The paper dictionaries and electronic dic- 
tionaries (pocket dictionaries) are most commonly used in students' classroom learning.

\section{Paper Dictionary}

In 1935 Michael West who had compiled the first English teaching dictionary called New Method English Dictionary. It has a history of about 80 years so far. At that time people had an idea that there should be a special English dictionary for foreign students. And after that, many kinds of paper dictionaries have been compiled. In 1947, the editors at Random House, aware of the rapid growth of English, published the first great dictionary of the postwar period: American College Dictionary (ACD). Edited by the noted lexicographer, Clarence L. Barnhart, the ACD revolutionized dictionary-making in the United States by introducing a number of innovations, among which was the inclusion of many new words and meanings. Then there are many famous English dictionaries such as Longman Dictionary of Contemporary English, Oxford Advanced Learner's Dictionary, the Merriam Webster Dictionary, and so on.

\section{Electronic Dictionary}

The definition of pocket electronic dictionary is to fix the contents into CMOS chip, put the corresponding information into the hardware electronic equipment, to refer and read the information through a certain interface. The pocket electronic dictionary is also called hand-held electronic dictionary and chip electronic dictionary (qtd. in Zhang, 2003). In 1983 the first English-German electronic dictionary was born in Germany, about 50 grams, just containing 4000 words, and it took three minutes to find out the word "cewichet". Since then, electronic dictionary development witnesses three periods to update. And we are familiar with the third and fourth generation ( $\mathrm{Lu}$, 2006). With the development of electronic technology, electronic dictionaries includes online dictionaries, CD-ROM dictionaries which can put the words into the computer and update on the internet. So it became a strong competitor to the paper dictionaries. And also many electronic dictionaries store the words from Oxford, Longman and other famous paper dictionaries, so they are more authoritative and comprehensive. The electronic dictionary is a new kind of source in these years and it is loved by more and more English learners for its convenience, speed and various-functions including its pronunciation, tests and even games for entertainment.

\section{English Dictionary Applications}

With the gradual improvement and development of the reformative teaching, the position of English dictionaries is upgrading continuously. To conduct students using dictionary correctly and efficiently, many educators transfer their researches to the skills of using dictionaries. In the field of English dictionary application and the learning of language, many experts have made empirical researches the use of English dictionaries, especially its influence on vocabulary acquisition and they have found that the main function of dictionaries is for readers to find out and check the meaning of the words. This will not only help the students to read and comprehend but also to improve the acquisition of vocabulary (Béjoint, 2002: p. 154). So for English learners, the English dictionary is one of the necessary tools for English learning. Then it is necessary for students to know what exactly the dictionary is and what its function is, and how to use it efficiently.

\section{Literature Review on Dictionary Researches}

Knight (1994) did a research on the impact of electrical dictionaries on vocabulary learning and reading comprehension. Students were divided into two groups at random, in which the experimental group was using the online dictionary while the control group was not. Subjects were supposed to read two short Spanish passages on line, and each word looked up in the dictionary would be recorded automatically. After reading, students were required to take some notes in English and later take two vocabulary tests. One test asked the students to explain Spanish words in English, and the other demanded them to choose the right answer from five alternatives. Tests were carried out two weeks later again in the same way so as to measure the effect of long-term memory. Results showed that compared to the controlled group, the experimental group excelled in both vocabulary learning and reading comprehension.

Summer (1988) did an experiment on the relationship between dictionary using and vocabulary acquisition. The subjects were randomly divided into four groups, only three of which could use the dictionaries. Among the dictionary-using groups, one was given definition; the second group was showed some examples; the third group provided with both; and the last one was not allowed to use dictionaries. It was found that any type of dictionary would benefit reading comprehension to some different degrees and the most effective one was the definition with examples. Therefore, he came to the conclusion: Though not a perfect tool, dictionaries have been proved very useful in bringing the students to a deeper understanding of the target language and helping them use the vocabulary correctly in writing.

There is no doubt that a good learning dictionary is not only the source for students to get English cultural knowledge but also a way to encourage them to learn by themselves for it can stimulate the students' interest in English learning. What's more, it is a useful tool to form habits of finding and solving problems by themselves, because using an English dictionary needs a certain skills. Hartmann and James (1998: pp. 206-220) indicate that the dictionary using skill is users' abilities to find out information, and this process refers to the users' behaviors, preferences and their habits.

Chen (2007) interviewed 189 freshmen and sophomores and made an on-the-spot investigation into their choices of English dictionaries, methods of finding words in dictionaries and others. She investigated the differences and similarities between English majors across different grades in dictionary skills and concluded that dictionary-using skills can not be automatically improved with students' English study, but by the instruction on dictionary-using. Teachers need to raise students' awareness of dictionaries using and provide necessary instructions and training.

Zhao (2004) investigated the English dictionary strategies of non-normal English major undergraduates, and discovered that the students did not know well how to use English dictionaries. Also teachers seldom supply any instructions to the students. Others such as Shi (2005), Pan and Wang (2007), Fan and Xiao (2006) and so on who had ever investigated students' dictionaries using all agreed that English learners need to choose the suitable dictionaries according to the characters of dictionaries and their own different English levels. At the same time, these 
researchers pointed out that the contents and compilation formats of a dictionary must accord with the need of users. They also emphasized the importance of teachers' instructions.

All these provide EFL learners with good advice and help. Some scholars have compared the paper dictionaries and electronic dictionaries. Zhang (2007) thought that there are pluses and minuses about the online dictionaries and paper dictionaries, and that paper dictionaries should not be discarded for the convenience of online dictionaries. These two kinds of dictionary are in a mutually complementary relationship, because electronic dictionaries are based on the contents of paper dictionaries. They both have advantages and disadvantages, and they can coexist and mutually complement each other for a long time on different occasions for different purposes.

So the popular opinion about the choice of paper and electronic dictionaries is that for language study, it is better to use paper dictionaries to get more details about the new words and on some urgent occasions when time is limited, and we need only to know the meaning of words or phrases, we can use electronic dictionaries.

But up till now, there are hardly any researches made on the language learners' dictionary-using patterns diachronically, i.e. their choice of dictionaries in different stages of language learning.

\section{Survey on the Diachronic Change of the Students' Dictionary Choosing}

\section{Participants}

The subjects involved in the research are 415 third-year English majors of a teachers' college in China, and 409 questionnaires are validly responded. Among the respondents, 384 are females and 31 males; 219 students are cultivated for teaching, 196 not for teaching. Their average age is 21.81 . These students are accomplishing the third-year university English courses. So they have formally learned English for nearly 9 years.

\section{Instruments}

The instruments used in the study include one questionnaire and the statistical software SPSS 15.0. The questionnaire was designed by the writer themselves to enquire about the subjects' English dictionaries using habits, which is composed of 9 questions, each of which is followed by 4 alternatives from which the participants are required to choose the one which is the best description of his own case. Each of these 9 questions is used to enquire about one of the subjects' 9 schooling years from junior middle to the third college year. The four choices are as the following:

1) When coming across a new word, I will not look it up in any dictionaries or reference books.

2) When coming across a new word, I will look it up in some electronic dictionary.

3) When coming across a new word, I will look it up in some paper dictionaries or reference books.

4) When coming across a new word, I will look it up in both some paper dictionary, and some electronic dictionary.

\section{Collection of the Data and Analysis}

The questionnaire was administered in at the beginning of the fourth academic year of the students' college life, and had received 409 valid questionnaires. The data collected from the questionnaire were treated SPSS. The statistics are mainly about the proportion of each pattern of dictionaries using.

\section{Analyses and Results}

\section{The Change in the Junior Middle School}

The frequency and percentage of the students' habit of dictionaries using in three junior middle school years are displayed in Table 1.

The statistics show that most students (55.6\%) in their first junior middle school year began to use the English dictionary and most of them used paper dictionaries. From grade 1 to grade 3 , the percentage of paper-dictionary users is on the increase $(46.0 \%, 54.8 \%, 62.1 \%)$. On the other hand, the students who do not use dictionaries take up nearly half of the total number in grade one, junior middle school, and then decrease to about $32.85 \%$, finally to $22.5 \%$. It is because with the deepening of the language learning process, the extra-curriculum reading is becoming possible and necessary, so the chances for the students to meet new words are become more and more. It can also be seen that students who use electronic dictionaries and those who use both electronic dictionaries and paper dictionaries are small in number. On the one hand, maybe in this period, English study task is not so heavy and most students are only focusing on their textbooks usually with explanations for new words. So paper dictionaries are the most popular choice for junior middle school students at this stage.

\section{The Change in the Senior Middle School}

The frequency and percentage of the students' habit of using dictionaries in three senior middle school years are displayed in Table 2.

It is shown that growing from a beginner to one mastering

Table 1.

Statistics for junior middle school period.

\begin{tabular}{ccccccc}
\hline & \multicolumn{2}{c}{ Grade one } & \multicolumn{2}{c}{ Grade two } & \multicolumn{2}{c}{ Grade three } \\
\cline { 2 - 7 } & Freq. & Per. & Freq. & Per. & Freq. & Per. \\
\hline 1 & 182 & 44.5 & 134 & 32.8 & 92 & 22.5 \\
2 & 22 & 5.4 & 28 & 6.8 & 38 & 9.3 \\
3 & 188 & 46.0 & 224 & 54.8 & 254 & 62.1 \\
4 & 17 & 4.2 & 23 & 5.6 & 25 & 6.1 \\
Total & 409 & 100.0 & 409 & 100.0 & 409 & 100.0 \\
\hline
\end{tabular}

Table 2.

Statistics for senior middle school period.

\begin{tabular}{ccccccc}
\hline & \multicolumn{2}{c}{ Grade one } & \multicolumn{2}{c}{ Grade two } & \multicolumn{2}{c}{ Grade three } \\
\cline { 2 - 7 } & Freq. & Per. & Freq. & Per. & Freq. & Per. \\
\hline 1 & 37 & 9.0 & 25 & 6.1 & 21 & 5.1 \\
2 & 51 & 12.5 & 58 & 14.2 & 62 & 15.2 \\
3 & 272 & 66.5 & 259 & 63.3 & 230 & 56.2 \\
4 & 49 & 12.0 & 67 & 16.4 & 96 & 23.5 \\
Total & 409 & 100.0 & 409 & 100.0 & 409 & 100.0 \\
\hline
\end{tabular}


a certain English skills, the students who are not using dictionaries are fewer and fewer $(9.0 \%, 6.1 \%$ to $5.1 \%)$. It is also shown that the students at this time have a stronger need to use dictionaries than when in junior middle school period. This is because that the National Matriculation English Text is approaching and English learning is becoming more and more pressing, so the students are seeking for opportunity to read out of class English materials. In such a process, it is unavoidable that they will meet a lot of new words whose meanings or usage are unavailable in their textbooks.

The students who are using paper dictionaries are on the decrease $(66.5 \%, 63.3 \%$ to $56.2 \%)$. On the contrary, the number of students who are using electronic dictionaries and those who are using both paper dictionaries and electronic dictionaries is becoming bigger and bigger (12.5\%, $14.2 \%$ to $15.2 \%$ and $12.0 \%, 16.4 \%$ to $23.5 \%$ respectively). Therefore in such a period, the students who use paper dictionaries are still the largest group about $66.5 \%$ - $56.2 \%$, though on the decrease and students who only use electronic dictionaries have come to the climax. It may be that in the process of extra-curriculum English reading, the students, most of times, pay only attention to the corresponding Chinese meanings of new words, so they do not want to take a long time to consult the paper dictionaries.

\section{The Change in the First Three College Years}

The frequency and percentage of the students' habit of dictionary using in the first three college years are displayed in Table 3.

It's very clear from the table that the number of students using both dictionaries becomes bigger and bigger (49.6\%, 61.5\% to $66.5 \%$ ), the students who only using electronic dictionaries and those who do not using any dictionaries are almost invariable in number. $(11.0 \%, 11.5 \%$ to $11.7 \%$ and $1.7 \%, 2.2 \%$ to $2.0 \%)$. In addition, the number of the students who only use paper dictionaries is on the decrease (37.7\%, $25.2 \%$ to $19.8 \%)$ which is much smaller than that in senior middle school $(66.5 \%$, $63.3 \%$ to $56.2 \%)$ and that in junior middle school (46.0\%, $54.8 \%$ to $62.1 \%$ ). It is because that in college, especially as English majors, they have more and heavier tasks of reading both extra- and intra-curricular English reading materials. Additionally, most of time there are no explanations for new words. So they have to consult their dictionaries and on some pressing occasions, they can only resort to the electronic dictionaries, while on some unhasty occasions, they will look up new words in paper dictionaries.

\section{Conclusion}

It can be seen from the above statistics that from junior to

Table 3.

Statistics for the first three college years.

\begin{tabular}{ccccccc}
\hline & \multicolumn{2}{c}{ Grade one } & \multicolumn{2}{c}{ Grade two } & \multicolumn{2}{c}{ Grade three } \\
\cline { 2 - 7 } & Freq. & Per. & Freq. & Per. & Freq. & Per. \\
\hline 1 & 7 & 1.7 & 9 & 2.2 & 8 & 2.0 \\
2 & 45 & 11.0 & 47 & 11.5 & 48 & 11.7 \\
3 & 154 & 37.7 & 103 & 25.2 & 81 & 19.8 \\
4 & 203 & 49.6 & 250 & 61.1 & 272 & 66.5 \\
Total & 409 & 100.0 & 409 & 100.0 & 409 & 100.0 \\
\hline
\end{tabular}

senior middle school, students incline to use paper dictionaries. But in universities, the number of students only using paper dictionary decreases to the second place. In their junior to senior middle school periods, the students incline to the unitary English dictionary using. However, when in university, they incline to use both kinds of dictionaries. The students who are not using dictionaries become fewer and few with the development of learners' English proficiency. Generally speaking, students using electronic dictionaries are not great in number all the time. This demonstrates that using paper dictionaries is the main stream of dictionary application.

The choice of English dictionaries can indicate a learner's ability of English learning and English dictionaries using is important for the cultivation of students' self-autonomy (Meng \& Su, 2003). So it is very important for teachers to instruct their students to use dictionaries effectively based on different stages of leaning to improve students' skills in using English dictionaries. It has been shown clearly in the Teaching Program for College English Majors that it is necessary for students to cultivate their ability to gain knowledge proficiently through using English dictionaries, encyclopedia and other reference books and to solve problems on language or other relevant background knowledge by themselves. In this research, it is found that there are many students who in their study of English still do not have the awareness of English dictionaries using or have not enough skills of English dictionaries using. This has also been supported in Dong's (2001) research.

Dictionaries play significant roles in language acquisition, for a teacher may not always be available and language learners need to be able to learn on their own for most of time. So how to choose a suitable English dictionary is crucial. Bilingual and monolingual dictionaries have their own characteristics, and English learners should make a choice at different stages in accordance with their own language proficiency and their different purposes to bring it into full play. It is advisable that the junior middle school students use bilingual dictionaries and some easy-to-read dictionaries, and the senior middle school students use the medium-sized dictionaries. It is a good phenomenon that in these two stages the great majority of students are using paper dictionaries. This will contribute a lot to the enhancement of their word knowledge.

And it is also a good phenomenon that advanced students in English study use both kinds of dictionaries. At such a stage, they need to learn as many new words as possible, so it's better to refer to both kinds of dictionaries. On the one hand, electronic dictionaries can immediately solve the problems in reading which is helpful to increase the learners' amount of reading. And on the other hand, book dictionaries elongate the time period of their contacting new words which will benefit the acquisition of new words. There are also some good English-English dictionaries which can provide a pure English context. Students can have more reading by the support of such dictionaries, and they do not need to transfer between their mother tongue and target language, which is a good way to train their thinking in English and enhance their comprehension of English. On the other hand, students can improve their accuracy in writing and speaking. Usually the learners do not need to worry about the English explanations, because these dictionaries are designed specially for the FLA students and the words in explanation have been screened.

All in all, language is a skill that can only be acquired through the learners' own efforts. They need to improve their 
reading efficiency with the help of their dictionaries and they need also to know about the dictionaries they are using with their teachers' instruction and help.

\section{REFERENCES}

Béjoint, H. (2002). An introduction of modern lexicography. Beijing: Foreign Teaching and Research Press.

Chen, Y. (2007). Differences and similarities of dictionary skills between English-majors in different years of study. Journal Beijing International Studies University, 10, 34-38.

Dong, Y. (2001). Direct and indirect 12 vocabulary learning in the communicative approach. Foreign Language Teaching and Research, 33, 125-129.

Fan, M., \& Xiao, D. (2006). A survey of EFL learners' use of English dictionaries: Toward understanding features of the good dictionary user. Yantai Normal University Journal (Philosophy and Social Sciences Edition), 23, 112-114.

Hartmann, R. R. K. (1985). Four perspectives on dictionary use: A critical review of research methods. In A. P. Cowie (Ed.), The dictionary and the language learner: Papers from the EURALEX Seminar at the University of Leeds (pp. 11-28). Tübingen: Max Niemeyer.

Hartmann, R. R. K., \& James, G. (1998). Dictionary of lexicography. London: Routledge. doi:10.4324/9780203159040

Knight, S. (1994). Dictionary use while reading: The effects on comprehension and vocabulary acquisition for students of different ver- bal abilities. The Modern Language Journal, 78, 285-299. doi:10.1111/j.1540-4781.1994.tb02043.x

Li, M., \& Zhou, J. (2001). An introduction to bilingual lexicography. Shanghai: Shanghai Foreign Language Education Press.

Lin, C., \& Liu, S. (2006). An introduction to English lexicography. Wuhan: Wuhan University Press.

Lu, G. (2006). The currency of pocket electronic dictionary and English teaching. Modern Enterprise Education, 21, 110-111.

Meng, Z., \& Su, L. (2002). A survey on non-English major college students' English dictionary using in Shanghai. In D. Zeng (Ed.), Research on criticism studies of bilingual language dictionaries.

Shi, B., \& Pan, P. (2005). Analysis of a survey on English learning dictionary using. Journal of Shanxi Coal-Mining Administrators College, 3, 78-79.

Summers, D. (1991). The role of dictionaries in language learning. In R. Carter, \& M. McCarthy (Eds.), Vocabulary and language teaching. London: Longman.

Wang, Y. (2007). On use of dictionary in English learning at different stages. Theory and Practice of Education, 27, 63-64.

Zhang, Q. (2007). On-line dictionaries and paper dictionaries. The Science Education Article Collects, 10, 223.

Zhang, Y. (2004). Computational lexicography and new-typed dictionaries. Shanghai: Shanghai Dictionary Press.

Zhao, W. (2004). A survey on the strategies of non-English major college students' English dictionaries using. Foreign Language World, 2, 29-24. 